\title{
EMPLOYEES AS INTERNAL STAKEHOLDERS IN THE CONCEPT OF SUSTAINABLE MARKETING - A COMPARATIVE ANALYSIS OF EUROPEAN AND ASIAN MARKET*
}

\author{
Edyta Rudawska** (i) http://orcid.org/0000-0003-4486-9456 \\ Sudath Weerasiri*** (i) http://orcid.org/0000-0002-5368-2688 \\ Małgorzata Wiścicka-Fernando**** (1) http://orcid.org/000-0001-9928-3335
}

\begin{abstract}
Background. Corporate sustainability has captured the attention of much of the world over the last few years. The idea of sustainability refers to all spheres of the company' activity, including marketing strategy. Before the company starts addressing sustainable marketing activities to external stakeholders effectively it needs to address them to its employees first. The reasons for that are two-fold. First, employees play a key role in the process of implementation of sustainable marketing strategies and programmes to external stakeholders, and thus they determine their effectiveness. Second, their sustainable behaviours performed in every-day work show that the company truly cares about sustainable development, and sustainable activities are not perceived as just cheap promotional, short-term actions. In this paper we assume that culture may differentiate employees' attitude towards sustainable marketing activities addressed to them and thus may differentiate sustainable marketing activities undertaken by company managers.
\end{abstract}

Research aims. To explore sustainable marketing activities used by companies towards employees in Europe and Asia, as well as to identify the differences in the

\footnotetext{
The paper is the result of an international research project grant financed by the National Science Centre in Cracow, entitled: "Sustainable marketing concept and its implementation in selected European markets - identification of international differences", Harmonia Funding, registration no. 2014/14/M/HS4/00891 (Principal investigator: Prof. Edyta Rudawska).

** Department of Marketing, University of Szczecin, Mickiewicza 64, Szczecin 71-101, Poland. E-mail: edyta@rudawska.pl

*** Department of Marketing Management, University of Kelaniya, Colombo, Western Province 11600, Sri Lanka. E-mail: sudath@kln.ac.lk

${ }_{* * * * *}^{*}$ Department of Marketing, University of Szczecin, Mickiewicza 64, Szczecin 71-101, Poland. E-mail: mwiscicka@wneiz.pl
} 
assessment of the scope of implementation of these activities by enterprises operating in the European and Asian markets.

Methodology. The empirical part of the paper is based on research results run among 262 MSMEs (micro, small, and medium enterprises) operating in Poland (a representative of the European market) and Sri Lanka (a representative of the Asian market). The respondents of the research comprised CEOs or CMOs. The research was run in 2016 and 2017. The non-parametric U Mann-Whitney test was used to examine the significance of the differences between the two countries. Factor analysis was also used to identify the way MSMEs in these two countries define sustainable marketing activities aimed at employees.

Key findings. The study revealed that differences between the two countries in relation to the assessment of sustainable marketing activities aimed at employees are statistically significant. Asian respondents assess them higher then Polish ones. To the best of the authors' knowledge this is the first in-depth study regarding the assessment of sustainable marketing activities aimed at employees. The study is a comparative analysis of the phenomenon between markets with different cultures - Poland (as an example of the European market) and Sri Lanka (as an example of the Asian market), which has not been previously researched.

Keywords: sustainability, internal marketing, employee engagement, company's stakeholders, Poland, Sri Lanka.

JEL Codes: M31, M38

\section{INTRODUCTION}

Nowadays, companies are considered by many to be the main player creating environmental and social problems and as a consequence to be the source of a lack of sustainability in society. Therefore, the concept of sustainable development and its rules are more commonly implemented at the level of individual organisations (Rogers, 2016). Sustainable development of the company refers to balancing the company's goals of economic nature with ecological and social ones (Lindfelt \& Törnroos, 2006; Medhurst, 2007; Liu, 2009; Vallance et al., 2011). To do it successfully the whole company culture and implemented strategies must be focused on sustainability. Becoming a sustainable organisation involves a continuing effort to build long-term relations with different groups of stakeholders (Sachs et al., 2009; Carroll et al., 2016). One of the most important are the company's employees (Lawrence \& Weber, 2017). Their unique role in the process of sustainability implementation is related to the fact that they determine the effectiveness of that process. Thus, their 
engagement in the concept, identification with it is inevitable in that process. They create as well and implement new, sustainable offers, strategies, processes and create long-term relations with company stakeholders in the way that improve environmental and social performance - all of which boost economic performance in the long run. They should view these strategies as essential to the company's success. Their every-day working behaviours and attitudes also serve building a sustainable company. The effective implementation of a company that thrives with a sustainable strategy cannot happen without strong employees' commitment at all levels of management - from the top to the bottom.

To ensure an internal support for the sustainable company's development managers should address sustainable marketing activities to employees for two key reasons. First, it should be stressed that sustainable strategy execution requires behavioural change by individuals in their every-day work and life. Eccles, Perkins, and Serafein (2012) indicate that for people to change their behaviour, they have to believe it is worth it. They have to understand and believe in the reasons for the change and recognise what they need to do to contribute to it. Only then employees will perform sustainable behaviours at work, when performing their duties. Therefore, the idea of sustainability should be constantly communicated to them and they should be regularly trained in social and environmental activities that the company undertakes. Secondly, the company has to act sustainably towards employees. They should fulfil employees' needs to enhance their satisfaction and motivation in the process of sustainability and create sustainable working conditions. Sustainable marketing should make employees want to identify with the company's sustainability strategy, commit themselves to that idea and engage in company success through implementing sustainable strategies.

The paper assumes that culture influences considerably employees' attitude towards work and therefore there are differences as far as work expectations are concerned due to differences in employees' cultural values. Research run so far in this area in different cultural contexts indicates, among others that Asian employees value work-life balance more (Bresman, 2015). On the contrary European employees value overtime compensation more. According to Bresman's (2015) research nearly a half of the Asian respondents declared they would give up 
a well-paid and prestigious job to gain better work-life balance. While most European employees said they would not.

In this paper we propose that the importance of sustainable marketing activities undertaken towards employees can vary between European and Asian employees. Therefore, companies should differentiate their sustainable marketing activities aimed at creating sustainable attitudes and behaviours of their employees. The aim of this paper is to explore sustainable marketing activities used by MSMEs towards employees as well as to identify the differences in the scope of the implementation of these activities by enterprises operating in the European and Asian markets.

The paper is based on field research run among Polish (as representatives of the European market) and Sri Lankan (as representatives of the Asian market) companies. This is the first in-depth study regarding a comparative analysis between these two countries. A quantitative approach was employed to gather data. The data was acquired via interviews with CEOs or MEOs of MSMEs operating in the selected countries. The results were developed through a quantitative analysis.

\section{EMPLOYEES AS THE COMPANY'S INTERNAL STAKEHOLDERS}

All companies operating in the market must interact with other organisations in their business environment to achieve their market and financial goals. Therefore, they have to build inter- and intra-organisational relationships. To understand a business is to know how these relationships work and with whom they should be created. According to De Witt (2017) contemporary business can be thus understood as a set of relationships among groups, which have a stake in the activities that make up business. Freeman, Harrison, and Wicks (2007) indicate that business is about how customers, suppliers, employees, financiers, communities and others, the so-called stakeholders, interact and create value. The stakeholder concept is widely discussed in recent management and marketing literature (Tantalo \& Priem, 2016; Schnackenberg \& Tomlinson, 2016; Kull et al., 2016; Hillebrand et al., 2015; Bourne, 2015). Company stakeholders are defined as any group and person that affect, or are affected by an organisation's decisions, policies, and operations. Theorists identify different approaches to 
stakeholder classification schemes (Kumar et al., 2016). The first, and the most commonly cited classification was proposed by Freeman (1984), who distinguished between internal stakeholders, those who are responsible for internal change and external stakeholders, those who are responsible for external change.

Considering this paper's concept a group of stakeholders that should be further focused on is the group of internal stakeholders. That group includes employees and company managers who are employed by the firm. Lawrence and Weber (2017) stress that they are "inside" the organisation, in the sense that they contribute their effort and skill, usually at a company's worksite. The role of employees as the company's stakeholder can be considered from two perspectives. On one hand, employees are the key driver of business performance (Skowron \& Skowron, 2013). They want to be a part of a bigger purpose. To implement a sustainable marketing strategy successfully they need to be engaged and they need to identify themselves with sustainable policies, common goals, and initiatives undertaken by the company they work for. The implementation of a sustainable marketing strategy will be more likely to succeed if the employees are involved in the decision-making process. Therefore, the company has to motivate them, create an organisational culture focused on sustainability, and engage people in social and ecological initiatives to influence their habits and attitudes. On the other hand, employees are also recipients of a company's sustainable policy. That is why employers should be responsible towards their employees. Taking care of appropriate working conditions, safety, health, etc., relates to a guarantee of sustainable development for companies in the long term. Activities connected with this tool of sustainable marketing can be divided into three principal groups:

1) compliance with labour rights, for example implementing non-discriminatory practices, ensuring the freedom of association, caring about work safety,

2) ensuring organisational order, manifested through transparency and openness, ethical behaviour towards employees, priority in offering work to local residents, etc.,

3) ensuring proper relations with employees by integrating them around sustainability initiatives, consulting employees with regard to sustainability marketing strategies. 


\section{ORGANISATIONAL CONTEXT OF CREATING EMPLOYEE ENGAGEMENT TOWARDS SUSTAINABILITY}

Employee engagement plays an important role in modern company management. How effectively objectives and tasks are accomplished depends on how far they are understood and accepted by employees. According to Kahn (1990) employee engagement concerns the degree to which individuals make full use of their cognitive, emotional, and physical resources to perform role-related work. Basing on the concept of Allen and Meyer (1991) and Shekary et al. (2012) three types of engagement can be identified: engagement arising from employees' attitude (emotional engagement), engagement arising from specific employees' behaviour (behavioural engagement), and engagement arising from the exchange of benefits between the employee and the employer (continuance engagement). Considering various types of employees' behaviour facilitates designing sustainable marketing activities, which in turn will make employees understand and accomplish sustainable goals better.

While planning the process of building employee engagement one should consider the following determinants: emotions, thinking, and acting (Cook, 2008). It is important to make employees emotionally engaged in what the company does. Temminck, Mearns, and Fruhen (2015) stress that emotional engagement facilitates the implementation of marketing strategies by the company. Thus, it influences the way employees think and act, accomplish their business goals and implement marketing strategies by the company.

As mentioned earlier in the paper the implementation of marketing activities in a sustainable way involves changes in management methods, in which economic, social, and environmental objectives should be taken into account. This broad perspective makes the role of those responsible for planning, implementing and developing these goals, i.e. senior staff, company's managers as well as middle-level employees (Caruana \& Chatzidakis, 2014; Hurth \& Whittlesea, 2017). They should be focused not only on implementing new processes, but also on engaging lower-level employees in them. This is of vital significance in order to accomplish the most important objective of sustainable marketing, i.e. meeting the current needs of customers 
and other company stakeholders while respecting the needs of future generations. Employees acting within sustainable marketing will, therefore be engaged in sustainable development (Sun et al., 2016).

The attitude and behaviour of company managers and owners will influence the extent to which other employees will get engaged and the scale of sustainable marketing implementation. This is the consequence of the role they play and the fact that they serve as a reference for all levels within the organisation. Wunder (2017) stresses that managers must therefore demonstrate a range of behaviours in conformity with sustainable marketing rules. That necessitates not only benefits for the customer, but also value proposition for other stakeholders. The question "What we do" is thus accompanied by the question "Why we do it". The example given by the managers, their support, and engagement in sustainable marketing implementation are the basis for accepting and following such behaviour among other employees. Referring to the research results, Kezar (2012) indicates that employee engagement in sustainable marketing activities helps generate more solutions and ideas, increase expertise, potential, enthusiasm, and sense of responsibility. Therefore, incorporating sustainable marketing strategies in the employee's tasks is as important as implementing sustainable marketing strategies outside.

The process of creating employee engagement involves three stages (Certo \& Certo, 2009). The process starts with managers' attitude towards sustainability as well as planning and creating activities on a strategic level in accordance with sustainable development rules. This is demonstrated among others in defining marketing objectives and planning sustainable marketing strategies, so that they become a part of the company's policy towards employees. The second stage involves accepting a specific approach towards sustainable marketing tools on an operational level. The assumption here is that the company's employees are internal customers (stakeholders). Thus, the process of employee engagement can be referred to the $5 \mathrm{C}$ concept, i.e. customer solution, customer cost, convenience, communication, and co-relations. Each element influences the process of implementation of sustainable marketing tools towards employees. As regards customer solution, it is important that employees are provided not only with economic benefits by the company, but also with social and environmental ones. As regards costs, the core dimension will include labour cost and the time dedicated to acquiring and implementing new tasks. Convenience 
relates to methods of acquiring new skills and knowledge. Employees can attend training and courses both internal and external in different areas, including sustainability. Communication is an important element of the process of engagement. One the one hand it is a platform where information on sustainability can be exchanged, but on the other hand, it can be used to promote sustainable activities, attitudes and ideas. It is also used by employees to communicate with external stakeholders. Additionally, sustainable communication will be used to disseminate sustainable rules and to build reliable and consistent messages. The last element which makes each employee co-create values for the company is co-relations. This element relates to building lasting relations between the company and the employee. The fact that employees can influence the company market position and effectiveness motivates managers to establish partnership relations and create employee loyalty. A successful relationship building requires managers to be open to employees' suggestions and to build their openness on integrity and fair play. Finally, the last stage involves control and further development of attitudes necessary to implement a sustainable strategy. It should be noted that the contemporary business environment changes dynamically and is volatile while sustainable development requires constant adaptation. That is why managers should control the progress made by employees in the process of sustainable strategy implementation as well as motivate, support, and provide further development of sustainable marketing activities towards employees. These activities can be defined as "long life sustainable behaviour". The employees become an indispensable tool to accomplish tasks and objectives set by a sustainable marketing-oriented companies (Certo \& Certo, 2009).

\section{RESEARCH CONTEXT AND METHODOLOGY}

This paper examines and compares sustainable marketing activities used by companies towards employees. It also focuses on identifying the differences in the assessment of the scope of implementation of these activities in Europe and Asia. The research was carried out in Poland, as an example of the European market, and Sri Lanka, as an example of the Asian market. Europe and Asia are two regions that have been undergoing significant changes in the last few decades. 
Researching these two regions seems crucial nowadays in the light of a debate about political but also the economic, social, and environmental crisis in Europe, which significantly impacts Asia (Christiansen et al., 2013). These two regions differ significantly. In developed regions such as Europe, issues regarding sustainability or company social responsibility referring to company employees gained researchers' attention quite a long time ago (Hill et al., 2011; Lozano, 2012; Ones \& Dilchert, 2012; Paillé \& Boiral, 2013; Norton et al., 2014). However, in developing countries, including Asian ones, there is still a long way to go to reach the level of the developed world (Chakraborty \& Mandal, 2014) and thus focus on sustainability. As Chakraborty and Mandal (2014) notice, companies operating there are still more concerned about financial results of strategies implemented in the market rather than social or environmental ones. However, a dynamic pace of development in Asian countries, including Sri Lanka, and thus increasing social and environmental problems will force companies to focus their programs and marketing strategies on sustainability to a greater extent. Over the last few decades, Asia in particular, has seen some enormous demographic changes, and as a consequence the process of urbanisation. These changes put pressure on existing economic, social, and environmental structures (United Nations Habitat, 2012). Therefore, in time it will make Asian companies take some steps to improve the quality of their services, and the whole business models, including creating "green jobs" to lower their negative impact on the environment (United Nations Habitat, 2012). Actually, as Roberts and Kanaley (2006) indicate that many promising initiatives that are improving the appealing conditions have actually already been undertaken, which put them on a path to a more sustainable future. Since, it can be perceived as a novelty, creating and implementing more sustainable business models in Asia can be perceived as a source of competitive advantage.

Implementing successfully sustainable marketing strategies by organisations starts from their employees. Therefore, companies will be increasingly introducing sustainability policies to encourage social and environmentally friendly behaviours among their work-force. Employee engagement in this process is the need of the hour in European and Asian countries. Employee engagement should be inter-organisational as well as intra organisational in nature. An employee should be motivated, have a thorough knowledge of organisational culture and 
should have enough belief in himself or herself to bring about a positive change by implementing new ideas.

Existing cultural diversity between the two regions, resulting from different religions, norms, values, variation in personality, experiences of individuals (Peerenboom, 2003), allow assuming the existence of differences in the employee's attitudes towards sustainable marketing activities addressed to them. Culture influences considerably the employee's attitude towards work. According to research run by INSEAD's Emerging Markets Institute, Universum, and the HEAD Foundation in 43 countries across Asia, Africa, Europe, the Middle East, and America in 2014 differences exist as far as work expectations are concerned (Bresman, 2015). However, to the best of the authors' knowledge there is no research examining differences in the perception of the importance of sustainable marketing practices aimed at employees in our two cultures. Thus, running research in two regions may provide very interesting insights in exploring the effectiveness of sustainable marketing tools and their influence on employee engagement both in Europe and Asia.

The research results presented in this paper are part of a research project dedicated to the concept of sustainable marketing implementation in MSMEs operating in Poland and Sri Lanka. The target population constituted CEOs, or eventually CMOs, if that position was present in the organisational structure of these organisations. The identification of that group as key research respondents for data collection is justified as in MSMEs it is them who take decisions on the selection of sustainable marketing tools towards employees. After building a rough draft of the questionnaire, it was consulted with selected MSMEs in both countries to examine the meaningfulness and the measures. Later, instrument pre-testing was conducted to ensure the measurement quality and the content validity. Pilot research was done by 30 managers of MSMEs. After that stage has been completed the research was run in 2016 and 2017. The convenience sampling approach was employed for collecting data. Before the final analysis of the results data screening was conducted. 38 questionnaires were eliminated because of missing data. The effective research sample totalled 262 MSMEs operating in Poland (a representative of the European market) and Sri Lanka (a representative of the Asian market). The sample included 150 respondents from Poland, comprising 57\% of the sample, and 112 respondents from Sri Lanka (43\%). As far as the 
company size is concerned most of the respondents were micro and small firms (equal percentage in both countries - 51\%). As for medium companies the vast majority (96\%) came from Poland (table 1).

Table 1. The structure of the sample total and with regard to the size of the company

\begin{tabular}{|c|c|c|c|c|}
\hline \multicolumn{5}{|c|}{ Total } \\
\hline & \multicolumn{2}{|c|}{ Number of companies } & \multicolumn{2}{|c|}{ Percentage } \\
\hline Poland & \multicolumn{2}{|c|}{150} & \multicolumn{2}{|c|}{57} \\
\hline Sri Lanka & \multicolumn{2}{|c|}{112} & \multicolumn{2}{|c|}{43} \\
\hline \multicolumn{5}{|c|}{ Company size } \\
\hline & \multicolumn{2}{|c|}{ Number of companies } & \multicolumn{2}{|c|}{ Percentage } \\
\hline & Poland & Sri Lanka & Poland (\%) & Sri Lanka (\%) \\
\hline Micro & 57 & 59 & 49 & 51 \\
\hline Small & 49 & 51 & 49 & 51 \\
\hline Medium & 44 & 2 & 96 & 4 \\
\hline
\end{tabular}

Source: own research.

The non-parametric U Mann-Whitney test was used to examine the significance of the differences between the two countries. Factor analysis was also used to identify the way MSMEs in the two countries define sustainable marketing activities aimed at employees. The questionnaire design involved identification of scale items on the employed construct named "sustainable employees". A total number of 7 items was incorporated in the questionnaire to accomplish the paper objectives. The items were anchored along a 5-point Likert scale ranging from 1 (strongly disagree) to 5 (strongly agree). All measures are self-reported. Therefore, the procedure of confirmatory factor analysis was used to determine whether specific relationships exist between the variables used in the study. Constructing measurement scales requires estimating the reliability of each of the analysed constructs. This reliability is most often communicated in the scientific literature by Cronbach's alpha, which measures internal consistency. This indicator was used in the study. 


\section{RESEARCH RESULTS}

Employees and company managers are strongly engaged in a critical relationship influencing company performance. To implement an external sustainable marketing strategy, managers need to address sustainability to their employees. Businesses cannot effectively operate in a sustainable way, if employees do not share ethical, environmental, or social values and norms communicated by the company. They need to feel that they are a part of a bigger purpose, but at the same time they need to feel that external sustainable marketing activities are a result of real managers' beliefs. Employees not only implement these activities but are recipients of a company's sustainable policy as well. That is why employers should be responsible towards their employees. Taking care of appropriate working conditions, safety, health, etc., relates to a guarantee of sustainable development for companies in the long term. In the current research the sustainable marketing tools aimed at employees comprise seven items:

1) in our company we try very hard to provide employees with a healthy and safe working environment - WE,

2) in our company we care about cooperative transparency and openness, implementing codes of ethics as an expression of concern for respecting employee values and norms - VN,

3) we try to strengthen attitudes related to environmental responsibility among our staff - ER,

4) we encourage employees to participate in company developed volunteer programmes - VP,

5) in the first instance we offer jobs to people from the region when we need to recruit new employees - NE,

6) we consult with and involve our employees in our strategic planning process - CI,

7) we have created a Work Life Balance programme - WLB.

As indicated in table 2 in both analysed countries sustainable marketing activities undertaken by managers towards employees are quite highly valued. Activities which are the most often implemented by MSMEs managers both in Poland and Sri Lanka are the very basic ones, often resulting from legal regulations. In both analysed countries providing employees with a healthy and safe working environment is the most important element of the sustainable strategy towards 
employees (WE $-\bar{X}=4.14$ and 4.34). In Poland the next most common elements refer to business ethics. Managers indicated that in the process of recruitment they first offer jobs to people from the region (NE $-\bar{X}=3.92)$ and that they focus on respecting employees' values and norms, caring about cooperative transparency and openness as well as implementing codes of ethics $(\mathrm{VN}-\bar{X}=3.84)$. Ethical cooperation and care for employees' values and norms is also appreciated by managers from Sri Lanka $(\mathrm{VN}-\bar{X}=4.19)$ - it was placed as the third most often implemented activity, following offering a Work Life Balance programme $-(\mathrm{WLB}-\bar{X}=4.21)$. The least used element of sustainable marketing in both countries is encouraging employees to participate in company developed was volunteer programmes (VP Poland $-\bar{X}=3.32$ and VP Sri Lanka $-\bar{X}=3.94)$, which shows that companies are considerably less inclined to implement activities that would involve their deeper commitment to the implementation of sustainable development strategies, in the sense of being related to their organisational culture, customs, etc. The data analysis also shows that the opinions of respondents in Sri Lanka are much varied compared to managers in Poland. The coefficient of variation (Vs) varies there from $32 \%$ to $36 \%$, while in Poland it oscillates between $21 \%$ and $36 \%$, depending on the analysed item.

Table 2. Assessment of sustainability marketing activities undertaken by companies towards employees

\begin{tabular}{|c|c|c|c|c|c|c|c|c|c|c|c|}
\hline \multirow[b]{2}{*}{ No. } & \multirow[b]{2}{*}{ Items } & \multicolumn{2}{|c|}{$\overline{\mathrm{X}}$} & \multirow{2}{*}{$\begin{array}{c}\mathrm{Z} \\
\text { (U Mann- } \\
\text {-Whitney } \\
\text { test) }\end{array}$} & \multirow{2}{*}{$\begin{array}{c}\text { Signif- } \\
\text { icance } \\
-p<.05\end{array}$} & \multicolumn{2}{|c|}{$\mathrm{M}$} & \multicolumn{2}{|c|}{$\mathrm{S}$} & \multicolumn{2}{|c|}{$\mathrm{Vs}$} \\
\hline & & Poland & $\begin{array}{c}\text { Sri } \\
\text { Lanka }\end{array}$ & & & Poland & $\begin{array}{c}\text { Sri } \\
\text { Lanka }\end{array}$ & Poland & $\begin{array}{c}\text { Sri } \\
\text { Lanka }\end{array}$ & Poland & $\begin{array}{c}\text { Sri } \\
\text { Lanka }\end{array}$ \\
\hline 1. & WE & $4.14^{*}$ & 4.34 & 2.62265 & .00 & 4.0 & 5.0 & 0.87 & 1.40 & 21.13 & 32.17 \\
\hline 2. & VN & 3.84 & 4.19 & 3.69863 & .00 & 4.0 & 4.0 & 0.88 & 1.37 & 22.79 & 32.70 \\
\hline 3. & ER & 3.85 & 3.98 & 1.52638 & .12 & 4.0 & 4.0 & 0.97 & 1.42 & 25.15 & 35.70 \\
\hline 4. & VP & 3.32 & 3.94 & 4.43221 & .00 & 4.0 & 4.0 & 1.20 & 1.39 & 36.12 & 35.38 \\
\hline 5. & $\mathrm{NE}$ & 3.92 & 3.98 & 0.26125 & .79 & 4.0 & 4.0 & 1.02 & 1.37 & 26.11 & 34.26 \\
\hline 6. & $\mathrm{CI}$ & 3.69 & 4.18 & 4.14215 & .00 & 4.0 & 4.0 & 1.05 & 1.41 & 28.50 & 33.63 \\
\hline 7. & WLB & 3.34 & 4.21 & 6.67340 & .00 & 4.0 & 4.0 & 1.18 & 1.43 & 35.47 & 33.86 \\
\hline
\end{tabular}

* Bold font indicates statistically significant differences between countries.

Source: own research. 
The findings presented in table 2 show relatively small differences with regard to the scope of sustainable marketing activities application in Poland and Sri Lanka. Nevertheless, for most of them, the two analysed groups can be differentiated in a statistically significant way. Statistically significant differences exist for the following five out of the seven analysed employee-related sustainable marketing items:

1) maintaining a balance between work and private life (WLB),

2) consulting with and involving company employees in the company's strategic planning process (CI),

3) encouraging employees to participate in volunteer programmes developed by the company (VP),

4) caring about cooperative transparency and openness, implementing codes of ethics as an expression of concern for respecting employee values and norms (VN),

5) providing employees with a healthy and safe working environment (WE).

In each of the five cases MSMEs' managers from Sri Lanka seem to be much more engaged compared to respondents from Poland as they show a greater involvement in activities in the above-mentioned areas.

The research study also provides some interesting insights on how managers of MSMEs in the two analysed countries understand and define sustainable marketing activities towards employees. For the purpose of this analysis we have named the theoretical latent construct as "sustainable employees - SEMP". The above-mentioned 7 items (measurement scales) were identified to define that construct. The 7 measurement scales of that construct were presented to respondents on a five-point Likert scale to determine the degree of acceptance for each statement. Next, a procedure of confirmatory factor analysis was used to determine whether specific relationships exist between the variables used in the study. Constructing measurement scales requires estimating the reliability of the analysed construct. Cronbach's alpha, which measures internal consistency, was used in the study. According to Hair et al. (2006) if $\alpha \geq 0.6$, the examined scale can be considered reliable. This coefficient makes it possible to determine whether the individual items of the scale for the analysed construct are correctly selected and consequently measure the true result (the correlation between the items is high). Assessments regarding the reliability of the "SEMP" construct are shown in table 3. 
Table 3. Reliability coefficients for the analysed construct

\begin{tabular}{|c|c|c|c|}
\hline \multirow{2}{*}{ No. } & \multirow{2}{*}{ Construct } & \multicolumn{2}{|c|}{ Reliability coefficient-Cronbach's $\mathbf{a}$} \\
\cline { 3 - 4 } & & Poland & Sri Lanka \\
\hline 1. & Sustainable employee - SEMP & .79 & .82 \\
\hline
\end{tabular}

Source: own compilation based on a printout of analyses conducted in Statistica 6.0.

The analysis shows that the created scales can be considered reliable. Cronbach's alpha, which represents the lowest limit of the reliability estimator, is very high. In order to determine the main factors describing the SEMP construct, the scree plot method was used in the analysis. The scree test showed that the construct in Poland is a two-factor construct and in Sri Lanka it is a one-factor construct (according to the rule of value $>1$ ) (table 4).

Table 4. Eigenvalues and percentages of variance

\begin{tabular}{|c|c|c|c|c|c|c|}
\hline \multirow{2}{*}{} & \multicolumn{3}{|c|}{ Poland } & \multicolumn{3}{c|}{ Sri Lanka } \\
\cline { 2 - 7 } & Eigenvalue & $\begin{array}{c}\text { \% of } \\
\text { variance }\end{array}$ & $\begin{array}{c}\text { Cumulative \% } \\
\text { of variance }\end{array}$ & Eigenvalue & $\begin{array}{c}\text { \% of } \\
\text { variance }\end{array}$ & $\begin{array}{c}\text { Cumulative \% } \\
\text { of variance }\end{array}$ \\
\hline & \multicolumn{5}{|c|}{ Sustainable employees - SEMP } \\
\hline 1. & 3.201 & 45.737 & 45.737 & 3.375 & 48.223 & 48.223 \\
\hline 2. & 1.115 & 15.940 & 61.677 & - & - & - \\
\hline
\end{tabular}

Source: own research.

Table 5. Factor loadings for items defining the latent constructs - sustainable employees (SEMP)

\begin{tabular}{|c|c|c|c|c|}
\hline \multirow{2}{*}{ No. } & \multirow{2}{*}{ Items } & \multicolumn{2}{|c|}{ Poland } & Sri Lanka \\
\cline { 2 - 5 } & & Factor 1 & Factor 2 & Factor 1 \\
\hline 1. & WE & 0.013948 & $\mathbf{0 . 8 1 0 3 2 0}$ & -0.629509 \\
\hline 2. & VN & 0.391676 & 0.570735 & $\mathbf{- 0 . 7 0 1 5 8 6}$ \\
\hline 3. & ER & $\mathbf{0 . 7 1 9 0 4 9}$ & 0.326024 & -0.663928 \\
\hline 4. & VP & $\mathbf{0 . 8 8 7 7 2 6}$ & -0.032338 & -0.675127 \\
\hline 5. & NE & 0.154944 & $\mathbf{0 . 7 1 3 4 1 5}$ & -0.655644 \\
\hline 6. & CI & 0.379573 & 0.665532 & $\mathbf{- 0 . 7 6 9 4 1 8}$ \\
\hline 7. & WLB & $\mathbf{0 . 7 3 7 5 4 9}$ & 0.324175 & $\mathbf{- 0 . 7 5 4 0 9 9}$ \\
\hline & Variance explained & 2.170755 & 2.146677 & 3.375638 \\
\hline & Share & 0.310108 & 0.306668 & 0.482234 \\
\hline
\end{tabular}

Source: own research. 
Table 5 shows the significant factor loadings in bold. In Poland, each of the two factors accounts for $31 \%$ of the overall variance explained by the initial set of 7 variables. The first factor is described by the variables relating to strengthening environmental responsibility among employees (ER), encouraging employees to participate in company' volunteer programmes (VP) as well as creating balance between work and private life (WLB). This factor was named "employee engagement in sustainability". The second factor defines sustainable employees in terms of healthy and safe working environment (WE), and offering jobs to people from the region in the first place (NE). Hence, this factor was named "working conditions".

As it was mentioned above, in Sri Lanka this construct consists of one factor, which accounted for almost $50 \%$ of the total variance explained by the initial set of variables. It is characterised by variables relating to cooperative transparency, codes of ethics and respecting employee values and norms (VN), consulting strategies with employees (CI), and implementing the work life balance programme (WLB). This factor was named "sustainable internal cooperation".

\section{CONCLUSIONS}

Globalisation, increased competition and other changes taking place in the business environment undoubtedly weakened the environmental and social standards, which made sustainability a priority in the process of creating new business models in the fight for competitive advantage (Lawrence \& Weber, 2017). Thus, for the last two decades the public, including business organisations has been rethinking the relationship between the natural and the economic environment. At the same time researchers are trying to provide rational and successful solutions to balance these two elements (natural environment and economic environment). The research in the field of sustainability focuses mainly on issues related to the sustainable production process, sustainable product, and sustainable cooperation in the value chain. This research is focused on employees as internal stakeholders in the concept of sustainable marketing in Europe and Asia. So far, addressing sustainability to employees has been a rather omitted field of interest in the research. Additionally, this study is a comparative analysis of these issues 
between Europe, with the focus on Poland and Asia region, which was represented by Sri Lanka.

The authors have identified the major differences between the two markets as far as the implementation of sustainable strategy towards employees is concerned. Since the European market is more developed than the Asian one and the two differ significantly in terms of culture, it was assumed that employees' attitude towards sustainable marketing activities addressed to them may be different. As a result, different sustainable marketing activities undertaken by company managers are implemented in both regions. This may also differentiate the way managers define the concept of sustainable employees. Because of this, the study can be considered as an original approach to comparative research. The empirical part of the research included 262 MSMEs operating in Poland and Sri Lanka and the respondents of the research comprised of CEOs or CMOs of the above-mentioned organisations.

The study has significantly contributed to the development of knowledge in the area of the sustainable marketing concept and sustainable human resource management. Moreover, the comparative approach to the study is an added value of the research concept. The research findings show that sustainable marketing activities aimed at employees are quite widely implemented by both European and Asian managers. It was actually surprising that in the case of most of the marketing tools analysed in the study, managers from Asia declared a higher level of implementation compared to European ones. It may result from the fact that in Asia the concept of sustainability is totally new and is a very hot topic as far as managing employees is concerned. It may be assumed that dynamically increasing new investments in Asia, based to a large extend on western capital, make Asian managers adopt strongly new ideas and management practices. Most of the differences in the assessment of the scope of implementation of these tools by Asian and European managers are statistically significant, so they distinguish the two regions significantly.

However, the results also show that activities, which are the most often implemented in both regions, are those resulting from legal regulations, according to which companies are in fact obliged to act. They include for example providing employees with a healthy and safely working environment. Other activities that show that the company is truly devoted to sustainability and convinced about the necessity 
of creating sustainable employees' behaviours and attitudes are implemented to a lesser extent both by European and Asian managers.

An interesting result of the research is also the fact that Asian managers compared to European ones focus much more on providing employees with a WLB programme. This supports the previous study by Bresman (2015).

The research study also provides some interesting insights on how managers in the two analysed regions understand and define sustainable marketing activities towards employees. European managers perceive the concept of a sustainable employee as engaging employees in sustainable activities, like volunteering programmes and strengthening their environmental responsibility as well as creating a sustainable working environment. In contrast, Asian managers perceive the concept of creating sustainable employees as focusing on transparency of the cooperation, respecting employees' values, implementing codes of ethics, and implementing WLB programmes.

\section{Managerial implications}

The economic value of the research is determined by its true contribution in the organisational results. In order to achieve business goals, any research related to the field of management should provide the best practices into the real world of business. Provided findings are vital for further improvement of the sustainable marketing processes of business organisations. At the same time, the study has opened many avenues to help integrate, design, and formulate sustainable marketing strategies for the benefit of employees and as a consequence of all the stakeholders in an organisation. Therefore, the research and its findings can be considered a useful tool to help incorporate best practices regarding sustainability among employees by managers of different organisations in both countries (Poland and Sri Lanka). According to the study, the employees' health and safety is paramount in both countries and the management of the analysed business organisations puts a lot of emphasis on this area which is also a vital part of going towards marketing sustainability. However, creating a healthy and safe working environment seems insufficient, nowadays. This research may be an inspiration for managers on how to create sustainability among employees and integrate them with the sustainable strategy of the whole company. Creating sustainable employees' behaviours and 
attitudes can translate into improved effectiveness and strengthening the company's market position in times of increased scrutiny from the public. This research contribution provides managers with a developed concept of creating sustainability among their employees.

\section{Limitations of the research}

We acknowledge that our research has some limitations that need to be addressed in future research. The first one is our exclusive reliance on MSMEs managers' opinions and declarations when researching issues regarding sustainable marketing activities undertaken towards employees. In the future, research exploring the employees' perception of these activities would be interesting. Another concern refers to the fact that the research was conducted only in two countries, one representing the European market (Poland) and the other one from the Asian market (Sri Lanka). Therefore, the results cannot be regarded as representative for these two markets, namely Europe and Asia. To address this limitation, future studies including other countries from these two regions are encouraged. Third, the research empirically shows inclusively the perspective of MSMEs. Although it was a conscious authors' decision to focus only on that sector, since it was not researched in this regard so far, future research aimed at comparison of big companies and MSMEs would be interesting. Finally, we have examined companies operating only in one industry, namely food\&drink industry. Future studies should investigate also other sectors.

\section{REFERENCES}

Allen, N. \& Meyer, J.P. (1991). A three-component conceptualization of organizational commitment. Human Resource Management Review, 1(1), 61-68.

Bourne, L. (2015). Making Projects Work. Effective Stakeholder and Communication Management. New York: CRC Press.

Bresman, H. (2015). What millenials want from work, charted across the world. Harvard Business Review, 23rd Feb, 1-8, https://hbr.org/2015/02/what-millennials-want-from-work-charted-across-the-world (accessed: 15th Dec 2018).

Carroll, A.B., Brown, J.A. \& Buchholtz, A.K. (2016). Business \& Society. Ethics, Sustainability \& Stakeholder Management. Boston: Cengage Learning. 
Caruana, R. \& Chatzidakis, A. (2014). Consumer social responsibility (CnSR): Toward a multi-level, multi-agent conceptualization of the "other CSR". Journal of Business Ethics, 121(4), 577-592.

Certo, S. \& Certo, T. (2009). Modern Management: Concepts and Skills. New Jersey: Pearson.

Chakraborty, A. \& Mandal, P. (2014). Understanding challenges of supply chain sustainability in Asia. International Journal of Management and Benchmarking, 4(1), 1-18.

Christiansen, T., Kirchner, E. \& Murray, P. (2013). Introduction. In: T. Christiansen, E. Kirchner \& P. Murray (eds.). The Palgrave Handbook of EU-Asia Relations (pp. 1-11). London: Palgrave Macmillan.

Cook, S. (2008). The Essential Guide to Employee Engagement. Better Business Performance through Staff Satisfaction. London: Kogan Page Limited.

De Witt, B. (2017). Strategy Synthesis. Hamshire (UK): Cengage Learning.

Eccles, R.G., Perkins, K. \& Serafein, G. (2012). How to become a sustainable company? MIT Sloan Management Review, 53(4), 43-50.

Freeman, R.E. (1984). Strategic Management: A Stakeholder Approach. Toronto: Pitman.

Freeman, R.E., Harrison, J.S. \& Wicks, A.C. (2007). Managing for Stakeholders. Survival, Reputation and Success. New Heaven: Yale University Press.

Hair, J.F. et al. (2006). Multivariate Data Analysis. Upper Saddle River: Prentice Hall.

Hill, L. et al. (2011). Employee green behaviors in Europe: A cross-cultural taxonomic investigation. In: S. Dilchert (Chair). Focusing on employees to achieve environmentally sustainable organizations. Symposium conducted at the 26th Annual Conference of the Society for Industrial and Organizational Psychology, Chicago (IL), http://doi.org/10.1037/e518362013-449 (conference presentation).

Hillebrand, B., Driessen, P.H. \& Koll, O. (2015). Stakeholder marketing: Theoretical foundations and required capabilities. Journal of the Academy of Marketing Science, 43(4), 411-428.

Hurth, V. \& Whittlesea, K. (2017). Characterising marketing paradigms for sustainable marketing management. Social Business, 7(3-4), 359-390.

Kahn, W.A. (1990). Psychological conditions of personal engagement and disengagement at work. Academy of Management Journal, 33(4), 692-724.

Kezar, A. (2012). Bottom-up / top-down leadership: Contradiction or hidden phenomenon. Journal of Higher Education, 83, 725-760.

Kull, A.J., Mena, J.A. \& Kirschun, D. (2016). A resource-based view of stakeholder marketing. Journal of Business Research, 69(12), 5553-5560. 
Kumar, V., Rahman, Z. \& Kazmi, A.A. (2016). Stakeholder identification and classification: A sustainability marketing perspective. Management Research Review, 39(1), 35-61.

Lawrence, A.T. \& Weber, J. (2017). Business and Society. Stakeholders, Ethics, Public Policy. New York: McGraw-Hill.

Lindfelt, L.-L. \& Törnroos, J.-Å. (2006). Ethics and value creation in business research: Comparing two approaches. European Journal of Marketing, 40(3/4), 328-351.

Liu, L. (2009). Sustainability: Living within one's own ecological means. Sustainability, 1, 1412-1430.

Lozano, R. (2012). Towards better embedding sustainability into companies' systems: An analysis of voluntary corporate initiatives. Journal of Cleaner Production, 25, 14-26.

Medhurst, J. (2007). A thematic evaluation of the contribution of structural funds to sustainable developments: Methods and lessons. In: U. Schubert \& E. Stoermer (eds.). Sustainable Development in Europe: Concepts, Evaluation and Applications (pp. 143-163). Cheltenham-Northampton: E. Elgar.

Norton, T.A., Zacher, H. \& Ashkanasy, N.M. (2014). Organizational sustainability and employee green behaviour: The mediating role of work climate perceptions. Journal of Environmental Psychology, 38, 49-54.

Ones, D.S. \& Dilchert, S. (2012). Environmental sustainability at work: A call to action. Industrial and Organizational Psychology: Perspectives on Science and Practice, 5, 444-466.

Paillé, P. \& Boiral, O. (2013). Proenvironmental behavior at work: Construct validity and determinants. Journal of Environmental Psychology, 36, 118-128.

Peerenboom, R. (2003). Beyond the universalism and relativism: The evolving debates about "values in Asia". Indiana International \& Comparative Law Review, 14(1), 1-85.

Roberts, B. \& Kanaley, T. (2006). Urbanization and sustainability in Asia. In: B. Roberts \& T. Kanaley (eds.). Urbanization and Sustainability in Asia. Case Studies of Good Practice. Asian Development Bank: Philippines (pp. 13-40), https://www.adb.org/sites/default/files/publication/27965/urbanization-sustainability.pdf (accessed: 15th Dec 2018).

Rogers, M. (2016). Six benefits of becoming a sustainable business. Environmental Leader, http://www.environmentalleader.com/2016/03/6-benefits-of-becoming-a-sustainable-business (accessed: 14th Dec 2018).

Sachs, S., Rühli, E. \& Kern, I. (2009). Sustainable Success with Stakeholders. The Untapped Potential. Hampshire: Palgrave Macmillan. 
Schnackenberg, A.K. \& Tomlinson, E.C. (2016). Organizational transparency: A new perspective on managing trust in organization-stakeholder relationships. Journal of Management, 42(7), 1784-1810.

Shekary, G. et al. (2012). The impact of internal marketing on organizational commitment in banking industry through structural equation modelling. Interdisciplinary Journal of Contemporary Research in Business, 3(9), 21.

Skowron, S. \& Skowron, Ł. (2013). Employee and customer satisfaction as the source of company's wealth. In: E. Weiss \& M. Pawęska (eds.). Enterprise - New Challenges, Theory and Practice (pp. 167-177). Alabama: York University.

Sun, Y., Garrett, T.C. \& Kim, K.H. (2016). Do Confucian principles enhance sustainable marketing and customer equity? Journal of Business Research, 69(9), 3772-3779.

Tantalo, C. \& Priem, R.L. (2016). Value creation through stakeholder synergy. Strategic Management Journal, 32(7), 314-329.

Temminck, E., Mearns, K. \& Fruhen, L. (2015). Motivating employees towards sustainable behaviour. Business Strategy \& The Environment, 24(6), 402-412.

United Nations Habitat (2012). Sustainable Urbanization in Asia. A Sourcebook for Local Governments, B. Barth \& F. Cabrera (eds.), http://mirror.unhabitat.org/ pmss/getElectronicVersion.aspx?nr=3345\&alt=1 (accessed: 13th Feb 2018).

Vallance, S., Perkins, H.A. \& Dixon, J.E. (2011). What is social sustainability? A clarification of concepts. Geoforum, 42(3), 342-348.

Wunder, T. (2017). Nachhaltige Geschäftsmodelle: Wirtschaftlichen mit gesellschaftlichem Mehrwert verknüpfen. Zeitschrift für Führung und Organisation, 86(6), 389-393. 